\title{
Dynamic Hyperglycemic Patterns Predict Adverse Outcomes in Patients with Acute Ischemic Stroke Undergoing Mechanical Thrombectomy
}

\author{
Giovanni Merlino ${ }^{1,2, *,+(\mathbb{C}) \text {, Carmelo Smeralda }}{ }^{2,3,+}{ }^{-}$, Massimo Sponza ${ }^{4}$, Gian Luigi Gigli ${ }^{2,5}$, \\ Simone Lorenzut ${ }^{1}$, Alessandro Marini ${ }^{2,3}{ }^{\oplus}$, Andrea Surcinelli ${ }^{2,3}$, Sara Pez ${ }^{2,3}$, Alessandro Vit ${ }^{4}$, \\ Vladimir Gavrilovic ${ }^{4}$ and Mariarosaria Valente ${ }^{2,3}$ \\ 1 Stroke Unit, Department of Neuroscience, Udine University Hospital, 33100 Udine, Italy; \\ simone.lorenzut@asufc.sanita.fvg.it \\ 2 Clinical Neurology, Udine University Hospital, 33100 Udine, Italy; carmelosmeralda@gmail.com (C.S.); \\ gigli@uniud.it (G.L.G.); alemarini00@gmail.com (A.M.); andsurcinelli@gmail.com (A.S.); \\ sarapez91@gmail.com (S.P.); mariarosaria.valente@uniud.it (M.V.) \\ 3 DAME, University of Udine, 33100 Udine, Italy \\ 4 Division of Vascular and Interventional Radiology, Udine University Hospital, 33100 Udine, Italy; \\ massimo.sponza@asufc.sanita.fvg.it (M.S.); alessandro.vit@asufc.sanita.fvg.it (A.V.); \\ vladimir.gavrilovic@asufc.sanita.fvg.it (V.G.) \\ 5 DMIF, University of Udine, 33100 Udine, Italy \\ * Correspondence: giovanni.merlino@asufc.sanita.fvg.it; Tel.: +39-043-255-2720 \\ $\dagger$ These authors contributed equally to this study.
}

Received: 5 May 2020; Accepted: 18 June 2020; Published: 20 June 2020

Abstract: Background: Admission hyperglycemia impairs outcome in acute ischemic stroke (AIS) patients undergoing mechanical thrombectomy (MT). Since hyperglycemia in AIS represents a dynamic condition, we tested whether the dynamic patterns of hyperglycemia, defined as blood glucose levels $>140 \mathrm{mg} / \mathrm{dl}$, affect outcomes in these patients. Methods: We retrospectively analyzed data of 200 consecutive patients with prospective follow-up. Based on blood glucose level, patients were distinguished into 4 groups: (1) persistent normoglycemia; (2) hyperglycemia at baseline only; (3) hyperglycemia at 24-h only; and (4) persistent (at baseline plus at 24-h following MT) hyperglycemia. Results: AIS patients with persistent hyperglycemia have a significantly increased risk of poor functional outcome (OR 6.89, 95\% CI 1.98-23.94, $p=0.002$, for three-month poor outcome; OR 11.15, 95\% CI 2.99-41.52, $p=0.001$, for no major neurological improvement), mortality (OR 5.37, 95\% CI 1.61-17.96, $p=0.006$, for in-hospital mortality; OR 4.43, 95\% CI 1.40-13.97, $p=0.01$, for three-month mortality), and hemorrhagic transformation (OR 6.89, 95\% CI 2.35-20.21, $p=0.001$, for intracranial hemorrhage; OR 5.42, 95\% CI 1.54-19.15, $p=0.009$, for symptomatic intracranial hemorrhage) after endovascular treatment. These detrimental effects were partially confirmed after also excluding diabetic patients. The AUC-ROC showed a very good performance for predicting three-month poor outcome (0.76) in-hospital mortality (0.79) and three-month mortality (0.79). Conclusions: Our study suggests that it is useful to perform the prolonged monitoring of glucose levels lasting 24-h after MT.

Keywords: hyperglycemia; acute ischemic stroke; large vessel occlusion; mechanical thrombectomy

\section{Background}

Mechanical thrombectomy (MT) is the first-line treatment for acute ischemic stroke (AIS) due to large vessel occlusion (LVO) [1]. Several randomized, controlled trials reported that MT improves the outcome, in comparison with the best medical therapy [2-6]. In these studies, the prevalence of 
good outcome at three months was as high as $71 \%$ [2-6]. However, data coming from observational registries reported a significantly lower rate of patients with functional independence; this ranged between $34 \%$ and 39\% [7-9]. In addition to blood pressure control and time to reperfusion, the glycemic status represents one of the most important modifiable predictors of adverse outcomes in patients undergoing MT [10-12].

Hyperglycemia impairs outcome in patients with AIS [13-15]. Among the several mechanisms implicated in this unfavorable association, it is important to remember that increased glucose levels in stroke patients alter the blood barrier permeability [16], exacerbate the thromboinflammatory cascade [17], induce acidosis [18], and increase oxidative stress response [19]. In AIS patients treated with alteplase, admission hyperglycemia has been associated with the increased risk of death, symptomatic intracranial hemorrhage (SICH), and poor functional status [20].

In recent years, the interest of the international scientific community shifted towards the role of altered glycemic status in affecting the outcome of AIS patients undergoing MT for LVO. Several studies observed that admission hyperglycemia reduced the likelihood of a good outcome in AIS patients treated with MT [21-24]. However, hyperglycemia may also occur during the post-operative period, both in diabetic and non-diabetic patients. A stress-response, characterized by excessive gluconeogenesis, glycogenolysis and insulin resistance with consequent hyperglycemia, is common after large strokes [25]. Recently, Li et al. investigated the role of post-operative hyperglycemia as a potential predictor of SICH in AIS patients treated with MT. The authors observed that, differently from glucose levels at admission, post-operative hyperglycemia increased the risk of the occurrence of $\mathrm{SICH}$ and parenchymal hematoma (PH) [26].

Since hyperglycemia in AIS represents a dynamic condition, we hypothesize that one isolated glucose test measure, performed at admission or within 24-h after MT, might be insufficient to understand the effects of the metabolic process on the ischemic brain. To date, only a few studies investigated the contribution of the dynamic patterns of hyperglycemia to stroke outcome [27-29]. These trials included only AIS patients treated and not treated with alteplase, whereas similar investigations in patients undergoing MT are lacking. We decided to perform this study with the aim of evaluating the impact of the dynamic patterns of hyperglycemia on stroke outcome, in AIS patients with LVO who were treated with MT.

\section{Methods}

\subsection{Patients}

This study is a retrospective analysis of consecutive patients with prospective follow-up admitted to the Udine University Hospital with AIS due to LVO, that were treated with MT from January 2015 to December 2019. Eligibility criteria for MT were the following: (1) presence of LVO in the anterior or posterior circulation, as revealed by CT angiography; (2) symptoms onset within $6 \mathrm{~h}$ for LVO in the anterior circulation and within $8 \mathrm{~h}$ for LVO in the posterior one; and (3) Alberta Stroke Program Early CT Score (ASPECTS) $>6$ on direct CT scan. In our center, the following exclusion criteria for MT are in use: (1) life expectancy less than 12 months; (2) severe internal medicine diseases with signs of organ failure; and (3) platelet count less than 55,000 mmc. All patients treated with MT in our center were included in this study. No specific exclusion criteria were adopted. Patients showing symptoms onset within $4.5 \mathrm{~h}$ received alteplase in accordance with the international guidelines [1].

The study was approved by our local Ethics Committee (Ref. No. CEUR-2020-Os-173). Informed consent was obtained from the participants in this study, or their representatives.

\subsection{Data Collection}

The following variables were collected: age, sex, vascular risk factors, laboratory findings, including glycated hemoglobin $(\mathrm{HbA} 1 \mathrm{c})$, admission systolic blood pressure, and pharmacological treatment. 


\subsection{Vascular Risk Factors}

Based on previous studies [30-32], we adopted the following definitions of vascular risk factors: (1) previous transient ischemic attack/stroke was defined if the patient had a history of ischemic (transient attack or stroke) or hemorrhagic cerebrovascular disease; (2) the presence of cardiovascular disease was based on the history of previous ischemic heart disease and/or revascularization treatment using percutaneous coronary intervention/coronary artery bypass grafting; (3) atrial fibrillation was defined if the patient had past medical history of atrial fibrillation that had been confirmed in medical records; (4) high blood pressure was defined as the history of hypertension and/or use of antihypertensive medication; (5) a history of diabetes mellitus that had been confirmed in medical records and/or use of insulin/oral hypoglycemic agents were considered for defining diabetes; (6) a presence of hypercholesterolemia was based on the use of lipid-lowering medications; (7) information on active tobacco use was used for defining patient as a current smoker.

\subsection{Measurement of Blood Glucose}

Blood glucose was measured at admission (baseline glucose level), before initiating any specific stroke treatment, and within $24 \mathrm{~h}$ after MT (post-operative glucose level). Based on previous studies on this topic, hyperglycemia was defined as a glucose level $>140 \mathrm{mg} / \mathrm{dL}$ [21-23]. Based on blood glucose level, patients were distinguished into 4 groups: (1) persistent normoglycemia, i.e., normoglycemia at baseline plus at 24-h; (2) hyperglycemia at baseline only; (3) hyperglycemia at 24-h only; and (4) persistent hyperglycemia, i.e., hyperglycemia at baseline plus at 24-h.

\subsection{Clinical Assessment}

\subsubsection{Trial of ORG 10,172 in Acute Stroke Treatment classification}

The trial of ORG 10,172 in acute stroke treatment (TOAST) classification was used to determine AIS subtypes based on their etiology. In particular, cerebrovascular events were distinguished as due to large artery atherosclerosis, cardioembolism, small-vessel occlusion, other determined etiology, and undetermined etiology [33].

\subsubsection{National Institute of Health Stroke Scale Score}

Stroke severity was determined with the National Institute of Health Stroke Scale (NIHSS) score, at admission and at discharge [34]. In accordance with many previous studies, we defined patients with major neurological improvement as those who had an improvement of $\geq 8$ points on the NIHSS from baseline or a NIHSS score of 0 at discharge [35-37].

\subsubsection{Modified Rankin Scale}

Functional outcome was assessed by means of the modified Rankin scale (mRS) at admission based on pre-stroke disability and 3 months after stroke [38]. The mRS score after discharge was recorded at the patients' routine clinical visit or through telephone interviews with the patients or their immediate caregivers. The mRS score was dichotomized into: favorable outcome (0-2) and poor outcome (3-6).

\subsubsection{Hemorrhagic Transformation}

The presence of intracranial hemorrhage (ICH) was defined as any PH based on the European Cooperative Acute Stroke Study (ECASS) morphologic definitions (ECASS PH-1 or PH-2) [39], whereas the presence of SICH was based on the ECASS-III protocol [40]. 


\subsection{Thrombectomy Procedure}

We collected the following information: site of the cerebral artery occlusion, distinguished in middle cerebral artery (MCA), tandem (ICA + MCA), and vertebrobasilar; type of device used for MT procedure, classified as thromboaspiration, stent retriever, thromboaspiration plus stent retriever, and permanent stenting; presence or absence of secondary embolization; time from symptom onset to MT; procedure duration; recanalization rate, assessed at the end of MT, using the thrombolysis in cerebral infarction (TICI) classification and defined as successful recanalization when a TICI $2 b-3$ was achieved.

\subsection{Outcome Measures}

The following endpoints were analyzed: 3-month poor outcome, no major neurological improvement at discharge, in-hospital mortality, 3-month mortality, presence of ICH, and presence of SICH. All the outcome measures were collected as part of our routine clinical practice in patients affected by cerebrovascular events.

\subsection{Statistical Analysis}

Data are displayed in tables as median and interquartile range (IQR).

Differences between the 4 groups were assessed by means of the Chi square test or the Fisher's exact test, when appropriate, for categorial variables. One-way analysis of variance for normally distributed continuous variables, and the Kruskal-Wallis test for non-normally distributed continuous variables and for ordinal variables were used. Post-hoc analysis was performed by means of the Bonferroni test. The Kolmogorov-Smirnov test with Lilliefors significant correction was used to assess the normal distribution of data.

Multiple logistic regression analysis was performed to test the impact of hyperglycemia risk groups, with reference to the normoglycemia group. The potential confounding variables included in the model were: age, $\mathrm{HbA} 1 \mathrm{c}$ values, use of antidiabetic drugs, intravenous thrombolysis before MT, baseline NIHSS score, pre-stroke mRS, time from symptom onset to MT, and successful recanalization. Systolic blood pressure $>180 \mathrm{mmHg}$ was added to other confounders in the analysis, that evaluated the association between hyperglycemic patterns and hemorrhagic transformation (i.e., ICH, SICH) [1]. Multivariate analysis was performed for all the sample population and, later, only for patients without diabetes (subjects with a history of diabetes and/or with $\mathrm{HbA} 1 \mathrm{c}$ values $\geq 6.5 \%$ were excluded from this analysis).

The utility of the hyperglycemic patterns in estimating unfavorable outcomes was tested with area under the receiver operating characteristic curve (AUC-ROC).

All probability values are two-tailed. A $p$ value $<0.05$ was considered statistically significant. Statistical analysis was carried out using the SPSS Statistics, Version 22.0 (Chicago, IL, USA).

\section{Results}

\subsection{Baseline Characteristics}

Among the 200 patients recruited during the study period, 116 (58\%) had persistent normoglycemia, whereas $36(18 \%)$ had elevated glucose only at baseline, 17 (8.5\%) only at 24 -h, and 31 (15.5\%) persistent hyperglycemia. Oral antidiabetic agents were taken by 21 patients $(10.5 \%)$, whereas only two patients were treated with insulin.

The general characteristics of the enrolled subjects are presented in Table 1. We did not observe any difference regarding age and sex between the 4 groups. The prevalence of diabetes mellitus and hypercholesterolemia was significantly higher in patients with persistent hyperglycemia than in the other three groups $(p=0.001)$. In addition, more than $80 \%$ of patients with persistent hyperglycemia was affected by hypertension. Compared to patients with persistent normoglycemia and baseline hyperglycemia, HbA1c values were significantly higher among subjects with persistent hyperglycemia 
$(p=0.001)$. Furthermore, these patients took slightly more antiplatelets. The use of alteplase before MT was similar among the groups. While admission NIHSS score was not different among the 4 groups, stroke severity at discharge was largely increased in patients with baseline and persistent hyperglycemia $(p=0.04)$.

Table 1. General characteristics of the subjects according to the hyperglycemic patterns.

\begin{tabular}{|c|c|c|c|c|c|}
\hline & $\begin{array}{c}\text { Persistent } \\
\text { Normoglycemia }\end{array}$ & $\begin{array}{c}\text { Baseline } \\
\text { Hyperglycemia }\end{array}$ & $\begin{array}{c}\text { 24-h } \\
\text { Hyperglycemia }\end{array}$ & $\begin{array}{c}\text { Persistent } \\
\text { Hyperglycemia }\end{array}$ & $p$ \\
\hline & $(n=116)$ & $(n=36)$ & $(n=17)$ & $(n=31)$ & \\
\hline \multicolumn{6}{|c|}{ Demographic data } \\
\hline Age, years & $73(67-80)$ & $75(68.2-82)$ & $75(66.5-78.5)$ & $72(69-79)$ & 0.7 \\
\hline Males, $n(\%)$ & $61(52.6)$ & $14(38.9)$ & $7(41.2)$ & $19(61.3)$ & 0.2 \\
\hline \multicolumn{6}{|c|}{ Vascular risk factors } \\
\hline $\begin{array}{l}\text { Previous transient ischemic } \\
\text { attack/stroke, } n(\%)\end{array}$ & $11(9.5)$ & $2(5.6)$ & $3(17.6)$ & $3(9.7)$ & 0.6 \\
\hline Cardiovascular disease, $n(\%)$ & $22(19.0)$ & $7(19.4)$ & $3(17.6)$ & $5(16.1)$ & 0.9 \\
\hline Atrial fibrillation, $n(\%)$ & $31(26.7)$ & $13(36.1)$ & $3(17.6)$ & $6(19.4)$ & 0.4 \\
\hline Hypertension, $n(\%)$ & $83(72.2)$ & $26(72.2)$ & $13(76.5)$ & $26(83.9)$ & 0.6 \\
\hline Diabetes mellitus, $n(\%)$ & $7(6.0)$ & $6(16.7)$ & $3(17.6)$ & $13(41.9)$ & 0.001 \\
\hline Hypercholesterolemia, $n(\%)$ & $25(21.6)$ & $9(25.0)$ & $1(5.9)$ & $13(41.9)$ & 0.03 \\
\hline Current smoking, $n(\%)$ & $21(18.1)$ & $7(19.4)$ & $5(29.4)$ & $9(29.0)$ & 0.5 \\
\hline \multicolumn{6}{|c|}{ Laboratory findings } \\
\hline HbA1c values, $\%$ & $5.7(5.4-6.0)$ & $6.0(5.7-6.4)$ & $6.0(5.9-6.4)$ & $6.4(5.8-7.1)$ & 0.001 \\
\hline Total cholesterol, mg/dL & $164(145-195.5)$ & $171(145-194)$ & $166(122.2-206.7)$ & $154(135.2-170)$ & 0.5 \\
\hline HDL cholesterol, mg/dL & $51(41-62)$ & $50(41-63.2)$ & $47.5(30.75-62.2)$ & $46(39-59)$ & 0.7 \\
\hline LDL cholesterol, mg/dL & $95(77-121.2)$ & $95.5(80-121.2)$ & $94.5(67.2-124.5)$ & $87(68-101)$ & 0.8 \\
\hline Triglycerides, mg/dL & $92(70-130.5)$ & $85(63-123)$ & $73.5(56.7-139)$ & $95(67.5-143.5)$ & 0.4 \\
\hline \multicolumn{6}{|c|}{ Blood pressure } \\
\hline $\begin{array}{l}\text { Systolic blood pressure, } \\
\text { mmHg }\end{array}$ & $151(130-170)$ & $155(143-163)$ & $154(145-168)$ & $155(138-180)$ & 0.7 \\
\hline \multicolumn{6}{|c|}{ Antithrombotic treatment at admission } \\
\hline Antiplatelets, $n(\%)$ & $28(24.1)$ & $13(36.1)$ & $5(29.4)$ & $14(45.2)$ & 0.1 \\
\hline Anticoagulants, $n(\%)$ & $16(13.8)$ & $6(16.7)$ & $2(11.8)$ & $3(9.7)$ & 0.9 \\
\hline \multicolumn{5}{|c|}{ Stroke subtypes based on TOAST classification } & 0.6 \\
\hline $\begin{array}{c}\text { Large arterial atherosclerosis, } \\
n(\%)\end{array}$ & $19(16.4)$ & $6(16.7)$ & $2(11.8)$ & $6(19.4)$ & \\
\hline Cardioembolism, $n(\%)$ & $60(51.7)$ & $16(44.4)$ & $10(58.8)$ & $14(45.2)$ & \\
\hline $\begin{array}{l}\text { Other determined etiology, } n \\
(\%)\end{array}$ & $6(5.2)$ & $0(0.0)$ & $0(0.0)$ & $0(0.0)$ & \\
\hline Undetermined etiology, $n(\%)$ & $31(26.7)$ & $14(38.9)$ & $5(29.4)$ & $11(35.5)$ & \\
\hline \multicolumn{6}{|c|}{ Baseline clinical characteristics } \\
\hline Alteplase use before MT, $n(\%)$ & $66(56.9)$ & $22(61.1)$ & $8(47.1)$ & $20(64.5)$ & 0.7 \\
\hline NIHSS score at admission & $16.5(13-20)$ & $19(15.2-22)$ & $17(14.5-19.5)$ & $18(15-22)$ & 0.2 \\
\hline NIHSS score at discharge & $3(1-8.7)$ & $9(2-16.7)$ & $7.5(1.7-17.7)$ & $12(2.5-16.5)$ & 0.04 \\
\hline Pre-stroke mRS $0-2, n(\%)$ & $103(88.8)$ & $34(94.4)$ & $17(100)$ & $28(90.3)$ & 0.4 \\
\hline
\end{tabular}

Table 2 summarizes information on MT in the four groups. No significant difference was observed among the groups. As expected, MCA was the most common site of LVO in the four groups. The combined technique using thromboaspiration plus stent retriever was adopted in a large part of our sample (43.5\%), whereas thrombectomy only with stent retriever was performed in only $6 \%$ of the patients. The median time between symptoms onset and MT was almost $220 \mathrm{~min}$, while the procedure length was $70 \mathrm{~min}$. The prevalence of successful recanalization was as high as $85 \%$. 
Table 2. Information on mechanical thrombectomy, according to the hyperglycemic patterns.

\begin{tabular}{|c|c|c|c|c|c|}
\hline & $\begin{array}{c}\text { Persistent } \\
\text { Normoglycemia }\end{array}$ & $\begin{array}{c}\text { Baseline } \\
\text { Hyperglycemia }\end{array}$ & $\begin{array}{c}\text { 24-h } \\
\text { Hyperglycemia }\end{array}$ & $\begin{array}{c}\text { Persistent } \\
\text { Hyperglycemia }\end{array}$ & $p$ \\
\hline & $(n=116)$ & $(n=36)$ & $(n=17)$ & $(n=31)$ & \\
\hline \multicolumn{5}{|c|}{ Site of LVO } & 0.5 \\
\hline $\mathrm{MCA}, n(\%)$ & $80(69.0)$ & $22(61.1)$ & $13(76.5)$ & $24(77.4)$ & \\
\hline Tandem, $n(\%)$ & $26(22.4)$ & $7(19.4)$ & $3(17.6)$ & $5(16.1)$ & \\
\hline Vertebrobasilar, $n(\%)$ & $10(8.6)$ & $7(19.4)$ & $1(5.9)$ & $2(6.5)$ & \\
\hline \multicolumn{5}{|c|}{ Type of device use for MT } & 0.6 \\
\hline Thromboaspiration, $n(\%)$ & $42(36.2)$ & $11(30.6)$ & $6(35.3)$ & $9(29)$ & \\
\hline Stent retriever, $n(\%)$ & $5(4.3)$ & $2(5.6)$ & $2(11.8)$ & $3(9.7)$ & \\
\hline $\begin{array}{l}\text { Thromboaspiration plus stent retriever, } n \\
(\%)\end{array}$ & $49(42.2)$ & $17(47.2)$ & $9(52.9)$ & $12(38.7)$ & \\
\hline Permanent stenting, $n(\%)$ & $20(17.2)$ & $6(16.7)$ & $0(0.0)$ & $7(22.6)$ & \\
\hline \multicolumn{6}{|c|}{ Other information on MT } \\
\hline Secondary embolization, $n(\%)$ & $6(5.2)$ & $4(11.1)$ & $3(17.6)$ & $3(9.7)$ & 0.3 \\
\hline Time from symptoms onset to MT, min & $210(170-260)$ & $236(205-270)$ & $225(195-310)$ & $210(155-255)$ & 0.08 \\
\hline Procedure length, $\min$ & $67.5(50-98.7)$ & $70(50-85)$ & $70(42.5-95)$ & $65(40-120)$ & 0.9 \\
\hline Successful recanalization rate, $n(\%)$ & $102(87.9)$ & $29(80.6)$ & $13(76.5)$ & $26(83.9)$ & 0.5 \\
\hline
\end{tabular}

MT: Mechanical thrombectomy; LVO: large vessel occlusion; MCA: middle cerebral artery.

\subsection{Association of Hyperglycemic Patterns with Clinical Outcomes in Univariate Analysis}

The rates of three-month poor outcome, three-month mortality, and SICH according to the hyperglycemic patterns are reported in Figures 1-3. The rates of three-month poor outcome, three-month mortality, and SICH prevalence of no major neurological improvement ( $24 \%$ for persistent normoglycemia, $55.9 \%$ for baseline hyperglycemia, $57.1 \%$ for 24 -h hyperglycemia, and $66.7 \%$ for persistent hyperglycemia, $p=0.001$ ), in-hospital mortality (10.3\% for persistent normoglycemia, $5.6 \%$ for baseline hyperglycemia, $17.6 \%$ for 24-h hyperglycemia, and $32.3 \%$ for persistent hyperglycemia, $p=0.006$ ), and ICH (19\% for persistent normoglycemia, $22.2 \%$ for baseline hyperglycemia, $11.8 \%$ for 24-h hyperglycemia, and $54.8 \%$ for persistent hyperglycemia, $p=0.001$ ) were statistically different among the four groups.

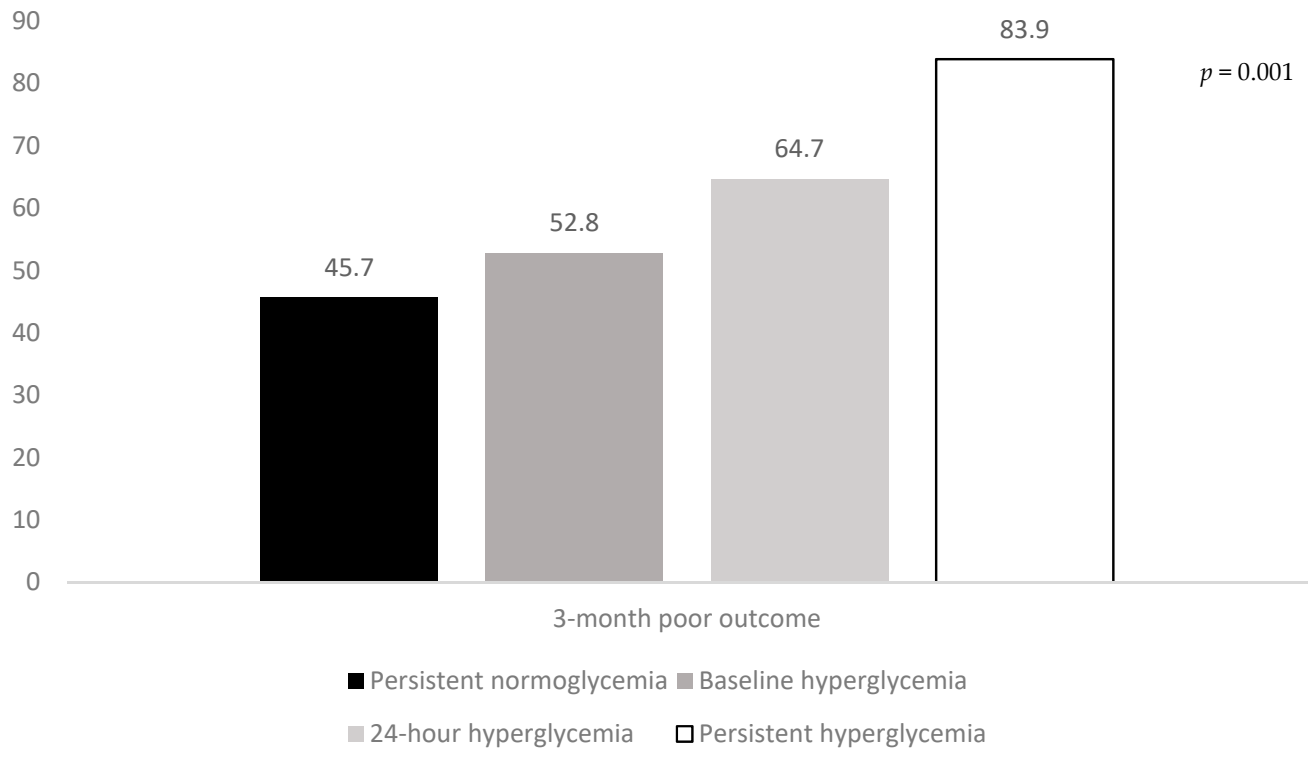

Figure 1. Rates of three-month poor outcome according to the hyperglycemic patterns. 


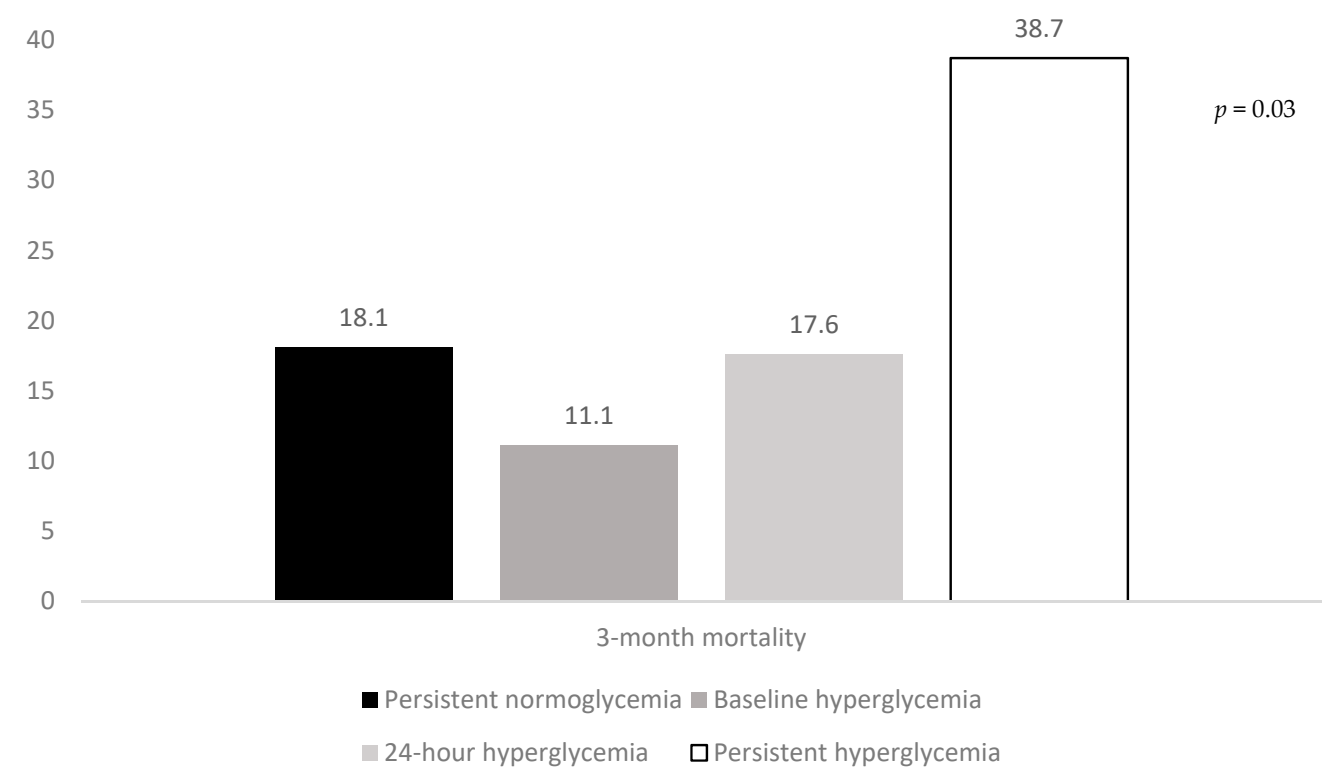

Figure 2. Rates of three-month mortality according to the hyperglycemic patterns.

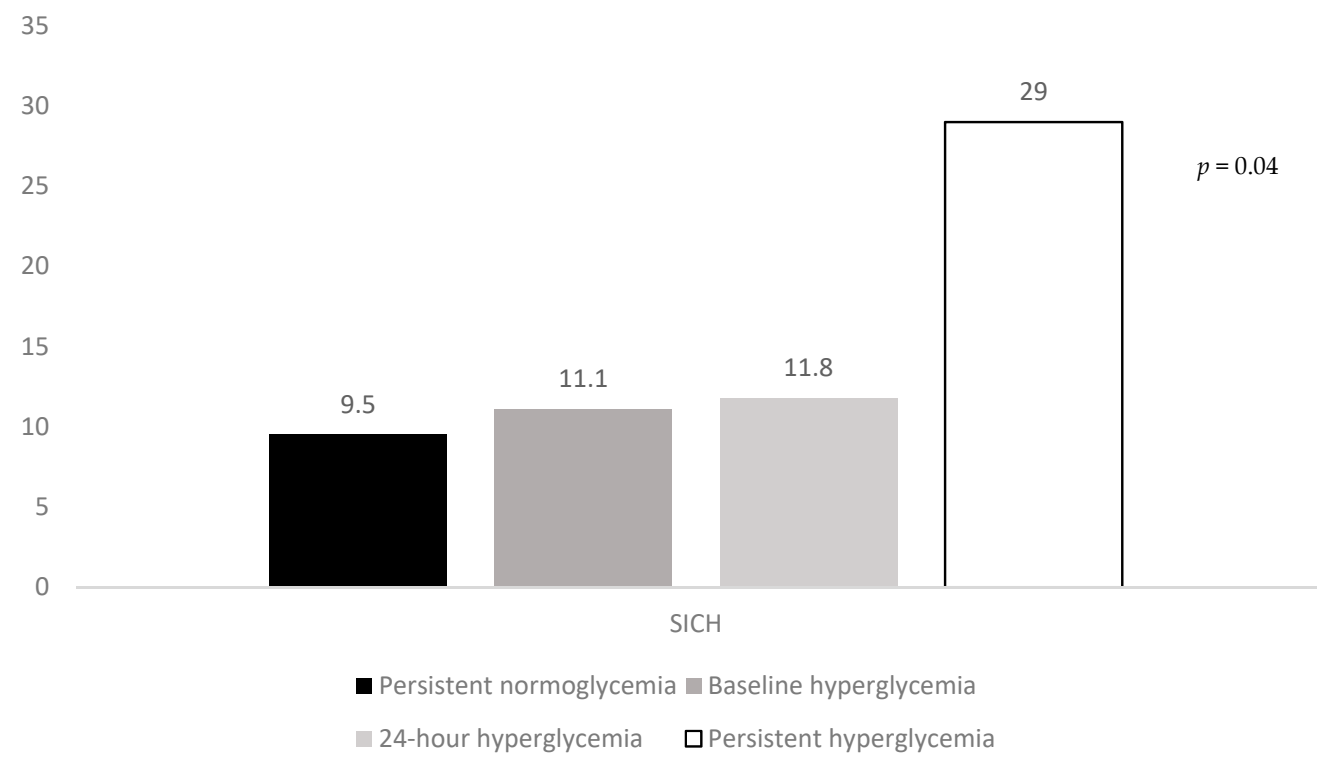

Figure 3. Rates of SICH according to the hyperglycemic patterns. SICH: symptomatic intracranial hemorrhage.

\subsection{Association of Hyperglycemic Patterns with Clinical Outcomes in Multivariate Analysis}

As reported in Table 3, all the outcomes were significantly associated with the presence of persistent hyperglycemia, even after controlling for confounders. Independent predictors, other than persistent hyperglycemia, were the following: (1) NIHSS score at admission (OR 1.11, 95\% CI 1.04-1.18, $p=0.002$ ) for three-month poor outcome; (2) baseline hyperglycemia (OR 3.37, 95\% CI 1.39-8.19, $p=0.007$ ), time from symptoms onset to MT (OR 1.01, 95\% CI 1.00-1.01, $p=0.02$ ), and successful recanalization (OR $0.22,95 \%$ CI $0.07-0.66, p=0.007$ ) for no major neurological improvement; (3) age (OR 1.06, 95\% CI 1.01-1.13, $p=0.05$ ), NIHSS score at admission (OR 1.13, 95\% CI 1.01-1.27, $p=0.04$ ), and successful recanalization (OR 0.31, 95\% CI 0.09-0.98, $p=0.04$ ) for in-hospital mortality; (4) age (OR 1.08, 95\% CI 1.02-1.13, $p=0.008$ ), and pre-stroke mRS (OR 1.52, 95\% CI 1.08-2.14, $p=0.02$ ) for three-month mortality; systolic blood pressure $>180 \mathrm{mmHg}$ for both (5) ICH (OR 3.33, 95\% CI 1.43.31-7.79, $p=0.005$ ), and (6) SICH (OR 9.69, 95\% CI 3.55-26.47, $p=0.001$ ). 
Table 3. Logistic regression model: adjusted ORs (95\% CIs) of hyperglycemic patterns, in relation to the respective outcomes.

\begin{tabular}{|c|c|c|c|c|}
\hline & $\begin{array}{c}\text { Persistent } \\
\text { Normoglycemia }\end{array}$ & $\begin{array}{c}\text { Baseline } \\
\text { Hyperglycemia }\end{array}$ & $\begin{array}{c}24-h \\
\text { Hyperglycemia }\end{array}$ & $\begin{array}{c}\text { Persistent } \\
\text { Hyperglycemia }\end{array}$ \\
\hline Three-month poor outcome ${ }^{\dagger}$ & 1 & $\begin{array}{c}0.99 \\
(0.41-2.38)\end{array}$ & $\begin{array}{c}1.75 \\
(0.54-5.67)\end{array}$ & $\begin{array}{c}6.89 \\
(1.98-23.94) \\
p=0.002\end{array}$ \\
\hline $\begin{array}{l}\text { No major neurological } \\
\text { improvement at discharge }\end{array}$ & 1 & $\begin{array}{c}3.37 \\
(1.39-8.19) \\
p=0.007\end{array}$ & $\begin{array}{c}3.41 \\
(0.96-12.16)\end{array}$ & $\begin{array}{c}11.15 \\
(2.99-41.52) \\
p=0.001\end{array}$ \\
\hline In-hospital mortality $^{\dagger}$ & 1 & $\begin{array}{c}0.39 \\
(0.07-2.12)\end{array}$ & $\begin{array}{c}2.67 \\
(0.58-12.30)\end{array}$ & $\begin{array}{c}5.37 \\
(1.61-17.96) \\
p=0.006\end{array}$ \\
\hline Three-month mortality $^{\dagger}$ & 1 & $\begin{array}{c}0.50 \\
(0.14-1.82)\end{array}$ & $\begin{array}{c}1.33 \\
(0.31-5.66)\end{array}$ & $\begin{array}{c}4.43 \\
(1.40-13.97) \\
p=0.01\end{array}$ \\
\hline Presence of $\mathrm{ICH}^{\ddagger}$ & 1 & $\begin{array}{c}1.15 \\
(0.43-3.08)\end{array}$ & $\begin{array}{c}0.45 \\
(0.08-2.44)\end{array}$ & $\begin{array}{c}6.89 \\
(2.35-20.21) \\
p=0.001\end{array}$ \\
\hline Presence of $\mathrm{SICH}^{\ddagger}$ & 1 & $\begin{array}{c}1.25 \\
(0.33-4.71)\end{array}$ & $\begin{array}{c}1.31 \\
(0.21-8.31)\end{array}$ & $\begin{array}{c}5.42 \\
(1.54-19.15) \\
p=0.009\end{array}$ \\
\hline
\end{tabular}

ICH: intracranial hemorrhage; SICH: symptomatic intracranial hemorrhage. ${ }^{\dagger}$ Adjusted for age, $\mathrm{HbA1c}$ values, use of antidiabetic drugs, intravenous thrombolysis, baseline NIHSS score, pre-stroke mRS, time from symptom onset to endovascular treatment, and successful recanalization. ${ }^{\ddagger}$ Adjusted for age, HbA1c values, use of antidiabetic drugs, intravenous thrombolysis, baseline NIHSS score, pre-stroke mRS, time from symptom onset to endovascular treatment, successful recanalization, and systolic blood pressure $>180 \mathrm{mmHg}$.

As summarized in Table 4, persistent hyperglycemia was independently associated with the outcome measures, with the exception of in-hospital mortality and three-month mortality, in non-diabetic patients. The independent predictors, other than persistent hyperglycemia, were the following: (1) age (OR 1.04, 95\% CI 1.00-1.08, $p=0.03$ ), and NIHSS score at admission (OR 1.12, $95 \%$ CI 1.04-1.20, $p=0.002$ ) for three-month poor outcome; (2) baseline hyperglycemia (OR 4.43, 95\% CI 1.57-12.53, $p=0.005$ ), 24-h hyperglycemia (OR 4.29, 95\% CI 1.01-12.53, $p=0.05$ ), time from symptoms onset to MT (OR 1.01, 95\% CI 1.00-1.01, $p=0.04$ ), and successful recanalization (OR 0.23, 95\% CI 0.06-0.84, $p=0.03$ ) for no major neurological improvement; (3) NIHSS score at admission (OR $1.19,95 \%$ CI 1.03-1.37, $p=0.01$ ), and successful recanalization (OR $0.19,95 \%$ CI $0.04-0.67, p=0.01$ ) for in-hospital mortality; (4) age (OR 1.08, 95\% CI 1.02-1.15, $p=0.009$ ), and pre-stroke mRS (OR 1.49, 95\% CI 1.01-2.20, $p=0.04$ ) for three-month mortality; and systolic blood pressure $>180 \mathrm{mmHg}$ for both (5) ICH (OR 3.76, 95\% CI 1.42-9.97, $p=0.008$ ), and (6) SICH (OR 6.91, 95\% CI 2.28-20.95, $p=0.001$ ).

Table 4. Logistic regression model in non-diabetic patients: adjusted ORs (95\% CIs) of hyperglycemic patterns in relation to the respective outcomes.

\begin{tabular}{|c|c|c|c|c|}
\hline & $\begin{array}{c}\text { Persistent } \\
\text { Normoglycemia }\end{array}$ & $\begin{array}{c}\text { Baseline } \\
\text { Hyperglycemia }\end{array}$ & $\begin{array}{c}24-h \\
\text { Hyperglycemia }\end{array}$ & $\begin{array}{c}\text { Persistent } \\
\text { Hyperglycemia }\end{array}$ \\
\hline three-month poor outcome ${ }^{+}$ & 1 & $\begin{array}{c}1.20 \\
(0.43-3.31)\end{array}$ & $\begin{array}{c}3.01 \\
(0.75-12.70)\end{array}$ & $\begin{array}{c}4.91 \\
(1.15-20.94) \\
p=0.03\end{array}$ \\
\hline $\begin{array}{l}\text { No major neurological } \\
\text { improvement at discharge }\end{array}$ & 1 & $\begin{array}{c}4.43 \\
(1.57-12.53) \\
p=0.005\end{array}$ & $\begin{array}{c}4.29 \\
(1.01-12.53) \\
p=0.05\end{array}$ & $\begin{array}{c}8.62 \\
(2.01-36.99) \\
p=0.004\end{array}$ \\
\hline In-hospital mortality ${ }^{+}$ & 1 & $\begin{array}{c}0.25 \\
(0.02-2.47)\end{array}$ & $\begin{array}{c}3.27 \\
(0.57-18.64)\end{array}$ & $\begin{array}{c}2.80 \\
(0.65-12.08)\end{array}$ \\
\hline three-month mortality ${ }^{+}$ & 1 & $\begin{array}{c}0.49 \\
(0.11-2.11)\end{array}$ & $\begin{array}{c}1.24 \\
(0.26-5.97)\end{array}$ & $\begin{array}{c}1.81 \\
(0.44-7.45)\end{array}$ \\
\hline Presence of $\mathrm{ICH}^{\ddagger}$ & 1 & $\begin{array}{c}0.93 \\
(0.28-3.03)\end{array}$ & $\begin{array}{c}0.16 \\
(0.01-1.84)\end{array}$ & $\begin{array}{c}7.15 \\
(1.98-25.76) \\
p=0.003\end{array}$ \\
\hline
\end{tabular}


Table 4. Cont.

\begin{tabular}{ccccc}
\hline & $\begin{array}{c}\text { Persistent } \\
\text { Normoglycemia }\end{array}$ & $\begin{array}{c}\text { Baseline } \\
\text { Hyperglycemia }\end{array}$ & $\begin{array}{c}\text { 24-h } \\
\text { Hyperglycemia }\end{array}$ & $\begin{array}{c}\text { Persistent } \\
\text { Hyperglycemia }\end{array}$ \\
\hline Presence of SICH ${ }^{\ddagger}$ & 1 & 1.26 & 1.27 & $\begin{array}{c}8.26 \\
(1.95-35.01) \\
p=0.004\end{array}$ \\
\hline
\end{tabular}

ICH: intracranial hemorrhage; SICH: symptomatic intracranial hemorrhage. ${ }^{\dagger}$ Adjusted for age, use of antidiabetic drugs, intravenous thrombolysis, baseline NIHSS score, pre-stroke mRS, time from symptom onset to treatment, and successful recanalization. $\ddagger$ Adjusted for age, use of antidiabetic drugs, intravenous thrombolysis, baseline NIHSS score, pre-stroke mRS, time from symptom onset to treatment, successful recanalization and systolic blood pressure $>180 \mathrm{mmHg}$.

\subsection{Predictive Value of Hyperglycemic Patterns}

In order to evaluate the diagnostic performance of the hyperglycemic patterns, as judged with AUC-ROC, we added them to the basic model that included the other independent predictors of each endpoint. After adding the hyperglycemic patterns to the basic model, the AUC-ROC value increased for predicting a three-month poor outcome from 0.70 (95\% CI 0.63-0.77) to 0.76 (95\% CI 0.69-0.82), for no major neurological improvement from 0.63 (95\% CI 0.55-0.72) to 0.75 (95\% CI 0.67-0.82), for in-hospital mortality from 0.69 ( $95 \%$ CI $0.59-0.78)$ to 0.79 (95\% CI $0.71-0.87$ ), for three-month mortality from 0.72 (95\% CI 0.63-0.81) to 0.79 (95\% CI 0.71-0.86), for ICH from 0.62 (95\% CI $0.52-0.71)$ to 0.70 (95\% CI $0.61-0.79)$, and for SICH from 0.71 (95\% CI 0.59-0.83) to 0.77 (95\% CI 0.66-0.88).

\section{Discussions}

In order to evaluate the impact of the dynamic patterns of hyperglycemia on stroke outcome in AIS patients with LVO treated with MT, we retrospectively analyzed the results observed in a series of consecutive patients with prospective follow-up. We demonstrated that AIS patients affected by LVO with persistent hyperglycemia, defined as blood glucose levels $>140 \mathrm{mg} / \mathrm{dL}$ at baseline plus at 24-h following MT, have a significantly increased risk of poor functional outcome, mortality, and hemorrhagic transformation after endovascular treatment. These detrimental effects were partially confirmed after also excluding diabetic patients.

Previous studies performed in AIS patients treated with MT used one isolated glucose test measurement at baseline for investigating the role of hyperglycemia as a predictor of unfavorable outcomes [21-24]. Taken together, results on admission hyperglycemia as a predictor of poor outcome in patients undergoing MT are contradictory, with some articles showing that hyperglycemia at admission was a predictor of a worse outcome $[22,24]$, and others showing no effect of blood glucose levels $[21,23]$. To date, only one study investigated whether hyperglycemia after MT was associated with a worse outcome. Li et al. analyzed 156 patients and reported that post-operative hyperglycemia $(1 \mathrm{mmol} / \mathrm{L}$ per increase, i.e., $18 \mathrm{mg} / \mathrm{dl}$ per increase) was an independent predictor of SICH (OR 1.20, 95\% CI 1.06-1.36, $p=0.008$ ) [26].

Differently from previous studies, we sought to investigate the clinical significance of the dynamic patterns of hyperglycemia in patients undergoing MT. Although no other study has been performed in this specific population, a post-hoc analysis of the ECASS-II trial lead the authors to conclude that, in addition to a single glucose measurement, the pattern of glycemic excursions should be considered in the prediction of stroke outcome [27]. A further study by Putaala et al. investigated 851 consecutive patients treated with alteplase. Differently from baseline normoglycemia, persistent and 48-h hyperglycemia predicted an unfavorable outcome, death, and SICH [28]. Similar results were reported by Yoo et al. [29]

Our findings show that the presence of glucose levels $>140 \mathrm{mg} / \mathrm{dL}$ at admission, plus at 24-h after MT, has harmful and detrimental effects, also in non-diabetic patients. It is very unlikely that this result may have been influenced by the use of alteplase prior to MT, since the use of alteplase was included in our multivariate analysis as confounder. A large number of patients with persistent hyperglycemia was functionally dependent at 3 months after stroke, their in-hospital and 
three-month mortality were as high as $32.3 \%$ and $38.7 \%$, respectively, and finally, almost $30 \%$ of these patients experienced SICH. Apart from the endpoint called "no major neurological improvement at discharge", patients with isolated admission hyperglycemia did not show any increased risk of adverse outcomes. Similarly, isolated hyperglycemia at 24-h after MT was not associated with a worse functional outcome, as well as a higher likelihood of death and SICH. Persistent hyperglycemia also had detrimental effects in non-diabetic patients. In fact, patients with this abnormal glycemic pattern had a higher risk of functional dependence and hemorrhagic transformation than those with persistent normoglycemia. Differently, the presence of persistent hyperglycemia was not associated with in-hospital and three-month mortality among non-diabetics undergoing MT for AIS.

In our sample, persistent hyperglycemia might impair outcomes as a marker of diabetes mellitus. In fact, patients with persistent hyperglycemia were more frequently affected by the chronic metabolic disease and they showed values of $\mathrm{HbA1c}$ significantly higher than subjects with different glycemic profiles. Epidemiologic studies have shown that diabetes is a well-established independent, but modifiable risk factor for stroke; both ischemic and hemorrhagic stroke [41]. There are several possible mechanisms wherein diabetes leads to stroke, among them diabetic vasculopathy could be considered. This pathophysiological hypothesis would be in agreement with the observed association between persistent hyperglycemia and hypercholesterolemia, a known risk factor for atherosclerosis. Furthermore, AIS patients with persistent hyperglycemia took slightly more antiplatelets. Although several clues point to diabetes as the link between persistent hyperglycemia and adverse outcomes in patients undergoing MT, nevertheless, the metabolic disorder alone cannot explain the worse prognosis of hyperglycemic patients. In fact, $\mathrm{HbA} 1 \mathrm{c}$ values did not represent an independent predictor of adverse outcomes in the multivariate analysis of our study.

Hyperglycemia occurs after an acute stress, such as stroke and myocardial infarction, by the activation of the hypothalamic-pituitary-adrenal axis [42,43]. Both human and animal studies showed that mortality rate, due to post-stress hyperglycemia, is high after both stroke and myocardial infarction [44]. Previous studies reported that post-stress hyperglycemia was strictly associated with stroke severity. Blood glucose increase was related to the severity of stroke in the study of Christensen et al. [45] Our results, regarding NIHSS score at discharge, are perfectly in line with these previous data. Moreover, we observed that persistent hyperglycemia was able to impair functional outcome and hemorrhagic transformation in non-diabetics. Thus, we postulate that post-stress hyperglycemia not only may occur, but also may cause severe consequences in AIS patients treated with MT.

The AUC-ROC analysis strongly supports the use of hyperglycemic patterns in order to predict outcomes in AIS patients with LVO undergoing MT.

Although our study would encourage to apply rigorous glycemic control for at least 24 -h following MT to achieve better outcomes, to date, no evidence supports the concept that ensuring strict post-stroke normoglycemia improves outcome. A possible reason for this might have been the severe hypoglycemia occurred in the intravenous insulin treatment group [46]. In order to overcome the failing of insulin, a phase 2 trial (the TEXAIS trial) on exenatide is now enrolling AIS patients in Australia, New Zealand, and Finland [47].

There are several limitations in our study. This is an observational study performed in a single center with a limited simple size. Although the study was retrospective, we prospectively collected data in consecutive patients. Information on the use of lowering glucose drugs during hospitalization is lacking. In addition, even after controlling for known confounders, residual confounding from unobserved factors might have affected our results. Information on last food intake before admission blood sample was not collected and the lack of a common criterion might have changed values, depending on the length of previous fasting. Unfortunately, no information other than NIHSS score were collected on clinical conditions at discharge, thus limiting the possibility of excluding their influence on measures of follow up at three months. Finally, the sample size was too small for performing further statistical analysis, e.g., propensity matching analysis, able to confirm our preliminary results. 
In conclusion, we demonstrated the utility of performing prolonged monitoring of glucose levels lasting 24-h after MT, instead of isolated blood glucose measurements. Further studies are needed to confirm these results in larger samples.

Author Contributions: Conceptualization, G.M. and C.S.; methodology, G.M. and C.S.; software, C.S. and S.L.; validation, S.L., G.L.G. and M.V.; formal analysis, G.M.; investigation, C.S., M.S., A.M., A.S., S.P., A.V., V.G.; data curation, G.M.; writing —original draft preparation, G.M.; writing—review and editing, G.M.; visualization, G.L.G.; supervision, M.V. All authors have read and agreed to the published version of the manuscript.

Conflicts of Interest: The authors declare that they have no competing interests.

\section{References}

1. Powers, W.J.; Rabinstein, A.A.; Ackerson, T.; Adeoye, O.M.; Bambakidis, N.C.; Becker, K.; Biller, J.; Brown, M.; Demaerschalk, B.M.; Hoh, B.; et al. American Heart Association Stroke Council. 2018 Guidelines for the early management of patients with acute ischemic stroke: A guideline for healthcare professionals from the American heart association/American stroke association. Stroke 2018, 49, e46-e110. [CrossRef]

2. Campbell, B.C.; Mitchell, P.J.; Kleinig, T.J.; Dewey, H.M.; Churilov, L.; Yassi, N.; Yan, B.; Dowling, R.J.; Parsons, M.W.; Oxley, T.J.; et al. EXTEND-IA Investigators. Endovascular therapy for ischemic stroke with perfusion-imaging selection. N. Engl. J. Med. 2015, 372, 1009-1018. [CrossRef] [PubMed]

3. Berkhemer, O.A.; Fransen, P.S.; Beumer, D.; van der Berg, L.A.; Lingsma, H.F.; Yoo, A.J.; Schonewille, W.J.; Vos, J.A.; Nederkoorn, P.J.; Wermer, M.J.; et al. MR CLEAN Investigators. A randomized trial of intraarterial treatment for acute ischemic stroke. N. Engl. J. Med. 2015, 372, 11-20. [CrossRef] [PubMed]

4. Goyal, M.; Demchuk, A.M.; Menon, B.K.; Eesa, M.; Rempel, J.L.; Thornton, J.; Roy, D.; Jovin, T.G.; Willinsky, R.A.; Sapkota, B.L.; et al. ESCAPE Trial Investigators. Randomized assessment of rapid endovascular treatment of ischemic stroke. N. Engl. J. Med. 2015, 372, 1019-1030. [CrossRef]

5. Saver, J.L.; Goyal, M.; Bonafe, A.; Diener, H.; Levy, E.I.; Pereira, V.M.; Albers, G.W.; Cognard, C.; Cohen, D.J.; Hacke, W.; et al. SWIFT PRIME Investigators. Stent-retriever thrombectomy after intravenous t-PA vs. t-PA alone in stroke. N. Engl. J. Med. 2015, 372, 2285-2295. [CrossRef] [PubMed]

6. Jovin, T.G.; Chamorro, A.; Cobo, E.; de Miquel, M.A.; Molina, C.A.; Rovira, A.; San Román, L.; Serena, J.; Abilleira, S.; Ribó, M.; et al. REVASCAT Trial Investigators. Thrombectomy within $8 \mathrm{~h}$ after symptom onset in ischemic stroke. N. Engl. J. Med. 2015, 372, 2296-2306. [CrossRef]

7. Merlino, G.; Sponza, M.; Petralia, B.; Vit, A.; Gavrilovic, V.; Pellegrin, A.; Rana, M.; Cancelli, I.; Naliato, S.; Lorenzut, S.; et al. Short and long-term outcomes after combined intravenous thrombolysis and mechanical thrombectomy versus direct mechanical thrombectomy: A prospective single-center study. J. Thromb. Thrombolysis 2017, 44, 203-209. [CrossRef]

8. Sallustio, F.; Koch, G.; Alemseged, F.; Konda, D.; Fabiano, S.; Pampana, E.; Morosetti, D.; Gandini, R.; Diomedi, M. Effect of mechanical thrombectomy alone or in combination with intravenous thrombolysis for acute ischemic stroke. J. Neurol. 2018, 265, 2875-2880. [CrossRef]

9. Minnerup, J.; Wersching, H.; Teuber, A.; Wellmann, J.; Eyding, J.; Weber, R.; Reimann, G.; Weber, W.; Krause, L.U.; Kurth, T.; et al. Outcome after thrombectomy and intravenous thrombolysis in patients with acute ischemic stroke: A prospective observational study. Stroke 2016, 47, 1584-1592. [CrossRef]

10. Cho, B.H.; Kim, J.T.; Lee, J.S.; Park, M.S.; Kang, K.W.; Choi, K.H.; Lee, S.H.; Choi, S.M.; Kim, B.C.; Kim, M.K.; et al. Associations of various blood pressure parameters with functional outcomes after endovascular thrombectomy in acute ischaemic stroke. Eur. J. Neurol. 2019, 26, 1019-1027. [CrossRef]

11. Maïer, B.; Dargazanli, C.; Bourcier, R.; Kyheng, M.; Labreuche, J.; Mosimann, P.J.; Puccinelli, F.; Taylor, G.; Le Guen, M.; Riem, R.; et al. Effect of steady and dynamic blood pressure parameters during thrombectomy according to the collateral status. Stroke 2020, 51, 1199-1206. [CrossRef] [PubMed]

12. Meinel, T.R.; Kaesmacher, J.; Mordasini, P.; Mosimann, P.J.; Jung, S.; Arnold, M.; Heldner, M.R.; Michel, P.; Hajdu, S.D.; Ribo, M.; et al. Outcome, efficacy and safety of endovascular thrombectomy in ischaemic stroke according to time to reperfusion: Data from a multicentre registry. Ther. Adv. Neurol. Disord. 2019, 12, 1756286419835708. [CrossRef] [PubMed]

13. Baird, T.A.; Parsons, M.W.; Phan, T.; Butcher, K.S.; Desmond, P.M.; Tress, B.M.; Colman, P.G.; Chambers, B.R.; Davis, S.M. Persistent poststroke hyperglycemia is independently associated with infarct expansion and worse clinical outcome. Stroke 2003, 34, 2208-2214. [CrossRef] [PubMed] 
14. Fuentes, B.; Castillo, J.; San José, B.; Leira, R.; Serena, J.; Vivancos, J.; Dávalos, A.; Nuñez, A.G.; Egido, J.; Díez-Tejedor, E. Stroke Project of the Cerebrovascular Diseases Study Group, Spanish Society of Neurology The prognostic value of capillary glucose levels in acute stroke: The GLycemia in Acute Stroke (GLIAS) study. Stroke 2009, 40, 562-568. [CrossRef] [PubMed]

15. Capes, S.E.; Hunt, D.; Malmberg, K.; Pathak, P.; Gerstein, H.C. Stress hyperglycemia and prognosis of stroke in nondiabetic and diabetic patients: A systematic overview. Stroke 2001, 32, 2426-2432. [CrossRef]

16. Rom, S.; Zuluaga-Ramirez, V.; Gajghate, S.; Seliga, A.; Winfield, M.; Heldt, N.A.; Kolpakov, M.A.; Bashkirova, Y.V.; Sabri, A.K.; Persidsky, Y. Hyperglycemia-driven neuroinflammation compromises BBB leading to memory loss in both diabetes mellitus (DM) type 1 and type 2 mouse models. Mol. Neurobiol. 2019, 56, 1883-1896. [CrossRef]

17. Desilles, J.P.; Syvannarath, V.; Ollivier, V.; Journé, C.; Delbosc, S.; Ducroux, C.; Boisseau, W.; Louedec, L.; Di Meglio, L.; Loyau, S.; et al. Exacerbation of thromboinflammation by hyperglycemia precipitates cerebral infarct growth and hemorrhagic transformation. Stroke 2017, 48, 1932-1940. [CrossRef]

18. Robbins, N.M.; Swanson, R.A. Opposing effects of glucose on stroke and reperfusion injury: Acidosis, oxidative stress, and energy metabolism. Stroke 2014, 45, 1881-1886. [CrossRef]

19. Won, S.J.; Tang, X.N.; Suh, S.W.; Yenari, M.A.; Swanson, R.A. Hyperglycemia promotes tissue plasminogen activator-induced hemorrhage by Increasing superoxide production. Ann. Neurol. 2011, 70, 583-590. [CrossRef]

20. Poppe, A.Y.; Majumdar, S.R.; Jeerakathil, T.; Ghali, W.; Buchan, A.M.; Hill, M.D. Canadian Alteplase for Stroke Effectiveness Study Investigators. Admission hyperglycemia predicts a worse outcome in stroke patients treated with intravenous thrombolysis. Diabetes Care 2009, 32, 617-622. [CrossRef]

21. Kim, J.T.; Jahan, R.; Saver, J.L. SWIFT Investigators. Impact of glucose on outcomes in patients treated with mechanical thrombectomy: A post hoc analysis of the solitaire flow restoration with the intention for thrombectomy study. Stroke 2016, 47, 120-127. [CrossRef]

22. Goyal, N.; Tsivgoulis, G.; Pandhi, A.; Dillard, K.; Katsanos, A.H.; Magoufis, G.; Chang, J.J.; Zand, R.; Hoit, D.; Safouris, A.; et al. Admission hyperglycemia and outcomes in large vessel occlusion strokes treated with mechanical thrombectomy. J. Neurointerv. Surg. 2018, 10, 112-117. [CrossRef] [PubMed]

23. Osei, E.; den Hertog, H.M.; Berkhemer, O.A.; Fransen, P.S.S.; Roos, Y.B.W.E.M.; Beumer, D.; van Oostenbrugge, R.J.; Schonewille, W.J.; Boiten, J.; Zandbergen, A.A.M.; et al. MR CLEAN Investigators. Admission glucose and effect of intra-arterial treatment in patients with acute ischemic stroke. Stroke 2017, 48, 1299-1305. [CrossRef] [PubMed]

24. Chamorro, Á.; Brown, S.; Amaro, S.; Hill, M.D.; Muir, K.W.; Dippel, D.W.J.; van Zwam, W.; Butcher, K.; Ford, G.A.; den Hertog, H.M.; et al. HERMES Collaborators. Glucose modifies the effect of endovascular thrombectomy in patients with acute stroke. Stroke 2019, 50, 690-696. [CrossRef] [PubMed]

25. Marik, P.E.; Bellomo, R. Stress hyperglycemia: An essential survival response! Crit. Care 2013, 17, 305. [CrossRef] [PubMed]

26. Li, F.; Ren, Y.; Cui, X.; Liu, P.; Chen, F.; Zhao, H.; Han, Z.; Huang, Y.; Ma, Q.; Luo, Y. Postoperative hyperglycemia predicts symptomatic intracranial hemorrhage after endovascular treatment in patients with acute anterior circulation large artery occlusion. J. Neurol. Sci. 2020, 409, 116588. [CrossRef] [PubMed]

27. Yong, M.; Kaste, M. Dynamic of hyperglycemia as a predictor of stroke outcome in the ECASS-II trial. Stroke 2008, 39, 2749-2755. [CrossRef]

28. Putaala, J.; Sairanen, T.; Meretoja, A.; Lindsberg, P.J.; Tiainen, M.; Liebkind, R.; Strbian, D.; Atula, S.; Artto, V.; Rantanen, K.; et al. Post-thrombolytic hyperglycemia and 3-month outcome in acute ischemic stroke. Cerebrovasc. Dis. 2011, 31, 83-92. [CrossRef]

29. Yoo, D.S.; Chang, J.; Kim, J.T.; Choi, M.J.; Choi, J.; Choi, K.H.; Park, M.S.; Cho, K.H. Various blood glucose parameters that indicate hyperglycemia after intravenous thrombolysis in acute ischemic stroke could predict worse outcome. PLoS ONE 2014, 9, e94364. [CrossRef]

30. Merlino, G.; Sponza, M.; Gigli, G.L.; Lorenzut, S.; Vit, A.; Gavrilovic, V.; Pellegrin, A.; Cargnelutti, D.; Valente, M. Prior use of antiplatelet therapy and outcomes after endovascular therapy in acute ischemic stroke due to large vessel occlusion: A single-center experience. J. Clin. Med. 2018, 7, 518. [CrossRef]

31. Chen, X.; Liu, Z.; Miao, J.; Zheng, W.; Yang, Q.; Ye, X.; Zhuang, X.; Peng, F. High Stress hyperglycemia ratio predicts poor outcome after mechanical thrombectomy for ischemic stroke. J. Stroke Cerebrovasc. Dis. 2019, 28, 1668-1673. [CrossRef] [PubMed] 
32. Zhu, B.; Pan, Y.; Jing, J.; Meng, X.; Zhao, X.; Liu, L.; Wang, Y.; Wang, Y.; Wang, Z. Stress hyperglycemia and outcome of non-diabetic patients after acute ischemic stroke. Front. Neurol. 2019, 10, 1003. [CrossRef]

33. Adams, H.P., Jr.; Bendixen, B.H.; Kappelle, L.J.; Biller, J.; Love, B.B.; Gordon, D.L.; Marsh, E.E., 3rd. Classification of subtype of acute ischemic stroke. Definitions for use in a multicenter clinical trial. TOAST. Trial of Org 10172 in Acute Stroke Treatment. Stroke 1993, 24, 35-41. [CrossRef] [PubMed]

34. Brott, T.; Adams, H.P., Jr.; Olinger, C.P.; Marler, J.R.; Barsan, W.G.; Biller, J.; Spilker, J.; Holleran, R.; Eberle, R.; Hertzberg, V.; et al. Measurements of acute cerebral infarction: A clinical examination scale. Stroke 1989, 20, 864-870. [CrossRef]

35. Brown, D.L.; Johnston, K.C.; Wagner, D.P.; Haley, E.C., Jr. Predicting major neurological improvement with intravenous recombinant tissue plasminogen activator treatment of stroke. Stroke 2004, 35, 147-150. [CrossRef] [PubMed]

36. Saposnik, G.; Di Legge, S.; Webster, F.; Hachinski, V. Predictors of major neurologic improvement after thrombolysis in acute stroke. Neurology 2005, 65, 1169-1774. [CrossRef]

37. Yaghi, S.; Hinduja, A.; Bianchi, N. Predictors of major improvement after intravenous thrombolysis in acute ischemic stroke. Int. J. Neurosci. 2016, 126, 67-69. [CrossRef] [PubMed]

38. van Swieten, J.C.; Koudstaal, P.J.; Visser, M.C.; Schouten, H.J.; van Gijn, J. Interobserver agreement for the assessment of handicap in stroke patients. Stroke 1988, 19, 604-607. [CrossRef]

39. Hacke, W.; Kaste, M.; Fieschi, C.; Toni, D.; Lesaffre, E.; von Kummer, R.; Boysen, G.; Bluhmki, E.; Höxter, G.; Mahagne, M.H.; et al. Intravenous thrombolysis with recombinant tissue plasminogen activator for acute hemispheric stroke. The European Cooperative Acute Stroke Study (ECASS). JAMA 1995, 274, 1017-1025. [CrossRef]

40. Hacke, W.; Kaste, M.; Bluhmki, E.; Brozman, M.; Dávalos, A.; Guidetti, D.; Larrue, V.; Lees, K.R.; Medeghri, Z.; Machnig, T.; et al. Thrombolysis with alteplase 3 to 4.5 hours after acute ischemic stroke. N. Engl. J. Med. 2008, 359, 1317-1329. [CrossRef]

41. Chen, R.; Ovbiagele, B.; Feng, W. Diabetes and Stroke: Epidemiology, Pathophysiology, Pharmaceuticals and Outcomes. Am. J. Med. Sci. 2016, 351, 380-386. [CrossRef] [PubMed]

42. Melamed, E. Reactive hyperglycaemia in patients with acute stroke. J. Neurol. Sci. 1976, 29, $267-275$. [CrossRef]

43. Sewdarsen, M.; Jialal, I.; Vythilingum, S.; Govender, G.; Rajput, M.C. Stress hyperglycaemia is a predictor of abnormal glucose tolerance in Indian patients with acute myocardial infarction. Diabetes Res. 1987, 6, 47-49.

44. Capes, S.E.; Hunt, D.; Malmberg, K.; Gerstein, H.C. Stress hyperglycaemia and increased risk of death after myocardial infarction in patients with and without diabetes: A systematic overview. Lancet 2000, 355, 773-778. [CrossRef]

45. Christensen, H.; Boysen, G. Blood glucose increases early after stroke onset: A study on serial measurements of blood glucose in acute stroke. Eur. J. Neurol. 2002, 9, 297-301. [CrossRef] [PubMed]

46. Johnston, K.C.; Bruno, A.; Pauls, Q.; Hall, C.E.; Barrett, K.M.; Barsan, W.; Fansler, A.; Van de Bruinhorst, K.; Janis, S.; Durkalski-Mauldin, V.L.; et al. Intensive vs standard treatment of hyperglycemia and functional outcome in patients with acute ischemic stroke: The SHINE randomized clinical trial. JAMA 2019, 322, 326-335. [CrossRef]

47. Muller, C.; Cheung, N.W.; Dewey, H.; Churilov, L.; Middleton, S.; Thijs, V.; Ekinci, E.I.; Levi, C.; Lindley, R.; Donnan, G.; et al. Treatment with exenatide in acute ischemic stroke trial protocol: A prospective, randomized, open label, blinded end-point study of exenatide vs. standard care in post stroke hyperglycemia. Int. J. Stroke 2018, 13, 857-862. [CrossRef]

(C) 2020 by the authors. Licensee MDPI, Basel, Switzerland. This article is an open access article distributed under the terms and conditions of the Creative Commons Attribution (CC BY) license (http://creativecommons.org/licenses/by/4.0/). 